\title{
RANCANG BANGUN IP PUBLIC BERBASIS VPN SERVER DAN PORT FORWARDING UNTUK MAIL SERVER PADA CV PACIFIC COMPUTER BATAM
}

\author{
Lex Saint Dry, S.SI. ${ }^{1)}$, Zainul Munir, S.T., M.e.T.C. ${ }^{2)}$ \\ 1 email: lexsaintdry@gmail.com \\ Program Studi Sistem Informasi, STMIK GICI \\ 2 email: bapakmunir@gmail.com \\ Program Studi Manajemen Informatika, STMIK GICI
}

\begin{abstract}
This research is oriented on Design IP Public based on VPN Server and Port Forwarding for Mail Server at CV. Pacific Computer Batam, is a network system that made to get IP Public from Cloud Service Provider. In this Digital Era, IP Public is hard to find on Internet packages sold in Indonesia in general, so the Author initiative to do this research in order to made company's Mail Server can work properly with IP Public. This research will use Server based on Linux with VPN Server technology that use L2TP/IPSec security.
\end{abstract}

Keyword : IP Public, VPN, Mikrotik, L2TP, IPSec, Mail Server, Linux

\section{PENDAHULUAN}

$V P N$ merupakan suatu bentuk jaringan pribadi yang melalui jaringan publik (Internet), dengan menekankan pada keamanan data dan akses global melalui internet. Hubungan ini dibangun melalui sebuah terowongan (tunnel) virtual antara 2 titik (peladen dan pengguna). Dengan menggunakan jaringan publik ini, pengguna dapat tergabung dalam jaringan lokal, mendapatkan hak dan pengaturan yang sama seperti ketika pengguna berada dikantor. (Loly Amalia Abdullah: 2006). Secara umum VPN adalah suatu proses dimana jaringan publik diamankan untuk memfungsikan sebagai jaringan pribadi. Sebuah VPN tidak didefinisikan sebagai rangkaian khusus atau rute, tetapi didefinisikan oleh mekanisme keamanan dan prosedur-prosedur yang hanya mengizinkan pengguna yang ditunjuk akses ke VPN dan informasi yang mengalir melaluinya. (Iqbal Amarullah: 2008)

Namun dalam kasus ini, peneliti akan memanfaatkan VPN berbasis L2TP dan IPSec ini sebagai wadah untuk memanfaatkan alamat protokol internet publik yang ada di Peladen berbasis Awan (Cloud Server) yang telah dibeli tersebut melalui metode port forwarding yang fungsinya akan meneruskan semua port ke Peladen yang ada di CV Pacific Computer.

Port Forwarding bertugas sebagai penerjemah alamat atau nomor port dari sebuah paket ke tujuan baru dan meneruskan paket sesuai dengan tabel routing yang telah dibuat.

1. Alamat Protokol Internet Pribadi/IP Privat (Private IP)
JURSIMA

Jurnal Sistem Informasi dan Manajemen https://ejournal.giciku.ac.id/ STMIK GICI 
Volume 5 No. 2

November 2017

Alamat Internet Protokol Internet Pribadi (Private IP) ini Hanya dapat digunakan pada jaringan lokal (LAN Local Area Network) dan tidak bisa diakses melalui jaringan internet secara langsung tanpa bantuan router (dengan

\section{konfigurasi NAT - Network Address} Translation). Alamat internet protokol pribadi digunakan untuk jaringan lokal (LAN) agar sesama komputer dapat saling berkomunikasi, misalnya digunakan di jaringan sekolah, kantor, toko,dan lainlain. perangkat keras kantor seperti printer, komputer, komputer laptop, telepon pintar tersebut semuanya menggunakan alamat protokol internet pribadi. Walaupun sudah terkoneksi ke internet, IP Privat tetap tidak bisa diakses langsung dari jaringan internet, karena dari sudut pandang Internet, IP privat terlihat seperti IP public yang digunakan untuk NAT (karena menggunakan ip privat dan menggunakan NAT IP Publik sebagai bantuan untuk terkonek ke Internet).

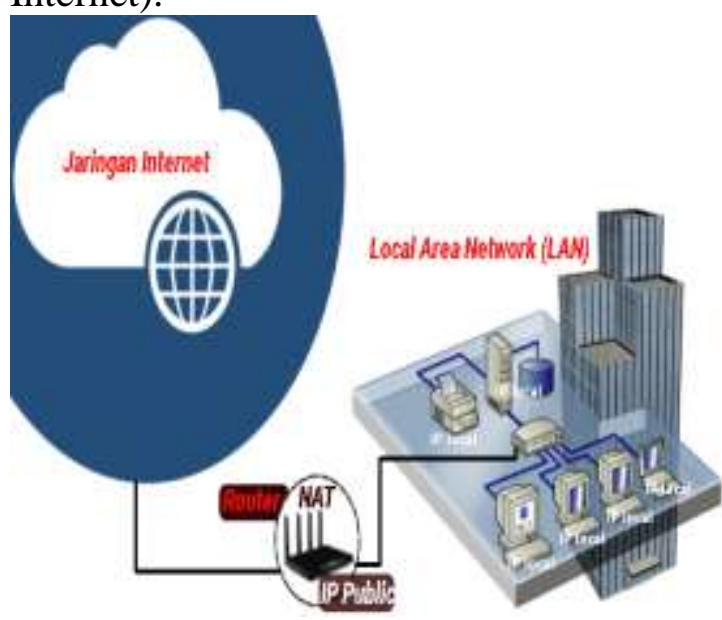

Gambar Penjelasan alamat protokol internet pribadi/IP Privat
IP privat persis seperti nomor telepon lokal/interkom/ekstensi PABX dalam sebuah kantor. Nomor lokal ekstensi PABX tidak dapat digunakan untuk menelepon ke luar dari lingkungan kantor (diluar PABX). Diperlukan Nomor telepon yang terdaftar (disebut juga IP public dalam hal ini) agar pengguna ekstensi PABX dapat menelepon ke semua nomor yang ada di dunia (disebut juga Internet dalam hal ini)

Dalam penggunaan IP privat, IP Privat tidak perlu didaftarkan/registrasi ke pihak otoritas sebelum digunakan karena penggunaan IP privat telah diatur, dialokasian dan distandarkan oleh IANA (Lembaga yang mengatur penggunaan dan pengalokasian IP) dalam terbitan RFC 1918 seperti tertera di bawah ini. Untuk IPv4 :

\begin{tabular}{|c|c|c|c|c|c|c|}
\hline $\begin{array}{l}\text { Mctyi } \\
\text { Netve }\end{array}$ & avrawe & 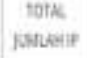 & 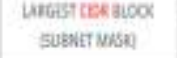 & $\begin{array}{l}\text { Hostio } \\
\text { set }\end{array}$ & $\begin{array}{l}\text { wax. } \\
\text { ant }\end{array}$ & $\begin{array}{l}\text { Cheswis } \\
\text { sescapiowemu }\end{array}$ \\
\hline $\begin{array}{l}\text { 2itht } \\
\text { beth }\end{array}$ & $\begin{array}{l}15060- \\
1125058285\end{array}$ & $16,7 \pi, 2 \%$ & 180000 1258.000 & $24 \mathrm{sh}$ & Soith. & Epe das A retweil \\
\hline $\begin{array}{l}\text { obst } \\
\text { atho. }\end{array}$ & $\begin{array}{l}12 \times 44- \\
12 n \times s 6 a s s\end{array}$ & $1,040,0 t$ & 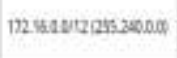 & ovith & 12 tent & $\begin{array}{l}16 \text { tomopastam I } \\
\text { retwicre }\end{array}$ \\
\hline $\begin{array}{l}\text { 16-4h } \\
\text { thot: }\end{array}$ & $\begin{array}{l}172.5800- \\
12.352 .25355\end{array}$ & es.5.54 & $\begin{array}{l}\text { 192 sandate } \\
\text { 185555:04 }\end{array}$ & Mals & 16ters: & $\begin{array}{l}25 \text { ienrigans dais6 } \\
\text { retovila }\end{array}$ \\
\hline
\end{tabular}

Gambar Klasifikasi alokasi IP Privat IPv4

Sedangkan untuk IPv6 adalah seperti gambar dibawah ini :

\begin{tabular}{|c|c|c|c|c|}
\hline FCCA19BB:COK & math & goteidepartcan & SMEt & 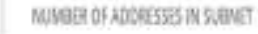 \\
\hline & \multicolumn{2}{|l|}{ If tha } & 1ites & satio \\
\hline $669: 18$ & 4 & 3:20xinks & $m y$ & 14,45,74,072,75,551,316 \\
\hline
\end{tabular}

Gambar Klasifikasi alokasi IP Privat IPv6
JURSIMA

Jurnal Sistem Informasi dan Manajemen https://ejournal.giciku.ac.id/ STMIK GICI 
Volume 5 No. 2

November 2017

\section{Port Forwarding}

Port forwarding atau pemetaan port adalah nama yang diberikan untuk teknik gabungan. Tujuannya memungkinkan port jaringan yang telah ditetapkan (asumsi protokol seperti TCP dan UDP, meskipun proses ini tidak terbatas) pada host dalam penyamaran NAT, biasanya jaringan pribadi, berdasarkan nomor port di mana ia diterima di gateway dari host asal. Port forwarding memungkinkan pengendalian komputer, misalnya dari Internet untuk menghubungkan ke komputer tertentu atau kamera ip dalam jaringan area lokal (LAN).

Untuk membantu dalam penyusunan penelitian ini, maka perlu adanya susunan kerangka kerja (frame work) yang jelas tahapan-tahapannya. Kerangka kerja ini merupakan langkah-langkah yang akan dilakukan dalam penyelesaian masalah yang akan dibahas.

Berdasarkan kerangka kerja penelitian yang telah ada, maka dapat diuraikan pembahasan masing-masing tahap dalam penelitian adalah sebagai berikut :

1. Studi Literatur

Pada tahap ini dilakukan pencarian landasan-landasan teori yang diperoleh dari berbagai buku dan juga internet untuk melengkapi perbendaharaan konsep dan teori, sehingga memiliki landasan dan keilmuan yang baik dan sesuai.

2. Membeli Peladen berbasis Awan melalui Biznet Gio Cloud

Pada tahap ini dilakukan pembelian Peladen berbasis Awan melalui Biznet Gio Cloud serta Alamat protokol internet publik statis, menyetel sistem operasi yang diperlukan.

JURSIMA

Jurnal Sistem Informasi dan Manajemen
3. Konfigurasi VPN Peladen berbasis Awan

Pada tahap ini dilakukan konfigurasi VPN Peladen agar bisa diakses disisi klien nantinya

4. Konfigurasi Mikrotik sebagai VPN Klien dan menghubungkan Peladen di CV Pacific Computer

Pada tahap ini dilakukan konfigurasi VPN Klien di Mikrotik agar koneksi dari VPN Peladen dapat digunakan di Peladen milik CV Pacific Computer

5. Konfigurasi Port Forwarding di Peladen berbasis Awan, dan Mikrotik di CV Pacific Computer

Pada tahap ini dilakukan konfigurasi port forwarding di peladen berbasis awan, serta di Mikrotik milik CV Pacific Computer agar koneksi alamat protokol internet publik dapat terhubung ke Peladen milik CV Pacific Computer

6. Analisa dan Ujicoba

Pada tahap ini dilakukan analisa atas konfigurasi yang telah dilakukan dan ujicoba koneksi apakah sudah stabil atau masih perlu perbaikan.

7. Pembuatan Laporan

Pada tahapan ini dilakukan pembuatan laporan yang disusun berdasarkan hasil penelitian dengan menggunakan teknik pengumpulan data primer dan sekunder sehingga menjadi laporan penelitian yang dapat memberikan gambaran secara utuh tentang sistem yang sedang dibangun.

\section{A. Analisis Sistem yang Berjalan \\ Terjadi gangguan pada surat elektronik CV Pacific Computer tidak dapat masuk ke peladen yang ada. Setelah ditelusuri lebih lanjut mengenai gangguan yang terjadi, ternyata gangguan yang terjadi}


Volume 5 No. 2

November 2017

karena router tidak mendapatkan IP

Publik Dinamis lagi, melainkan sebuah IP

Privat yang tidak dapat digunakan untuk

Peladen yang dimiliki oleh CV Pacific

Computer. Saat ini pada CV Pacific Computer terdapat beberapa Peladen, diantaranya adalah Peladen Surat Elektronik (Mail Server) yang membutuhkan IP Publik untuk berkomunikasi dengan seluruh dunia, baik IP Publik Statis maupun Dinamis tidak menjadi masalah. Pada CV Pacific Computer saat ini sedang berlangganan paket internet Indihome dari Telkom dengan kecepatan 20Mbps untuk unduh, 4Mbps untuk unggahnya dengan mendapatkan alokasi IP Publik dinamis sebelumnya, dan dapat disiasati perubahan alamat IP nya dengan berlangganan layanan pihak ketiga, disini CV Pacific Computer menggunakan DynDNS sebagai layanan pengganti IP Publik Dinamis dengan sebuah domain. Contohnya yang akan didapat adalah namadomain.dyndns.tv . Alamat tersebut mempermudah pengguna mengenali alamat IP Publik yang mereka miliki tanpa harus mengingat alamat IP Publiknya, cukup hanya dengan mengingat namadomain.dyndns.tv sebagai alamat IP Publiknya untuk keperluan lebih lanjutnya, serta menggunakan port forwarding untuk meneruskan koneksi dari Peladen ke Internet.

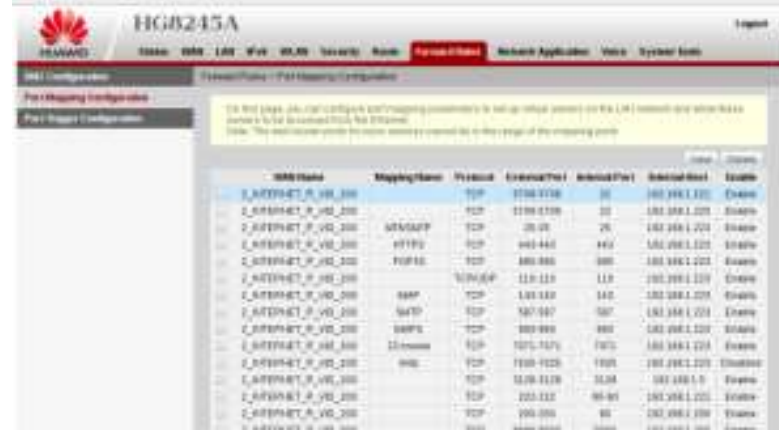

Gambar Port Forwarding pada Router Huawei

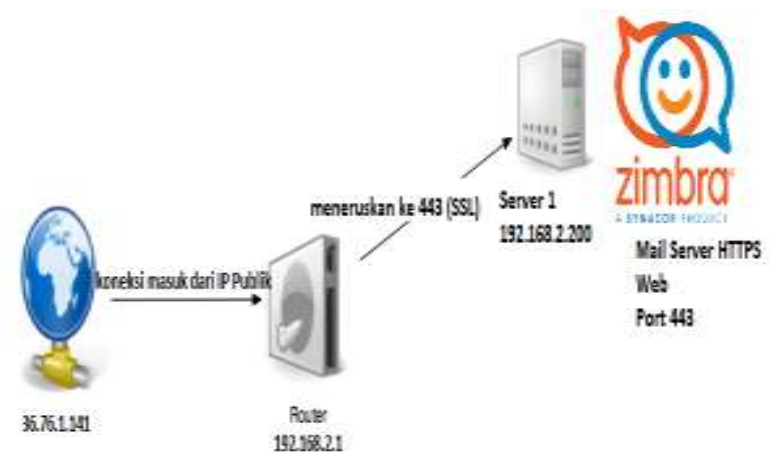

Gambar Skema Koneksi CV Pacific Computer sebelumnya

Namun dibeberapa minggu terakhir, terjadi gangguan yang menyebabkan surat elektronik tidak dapat masuk. Setelah ditelusuri lebih lanjut mengenai gangguan yang terjadi, ternyata gangguan yang terjadi karena router tidak mendapatkan IP Publik Dinamis lagi, melainkan sebuah IP Privat yang tidak dapat digunakan untuk Peladen yang dimiliki oleh CV Pacific Computer.

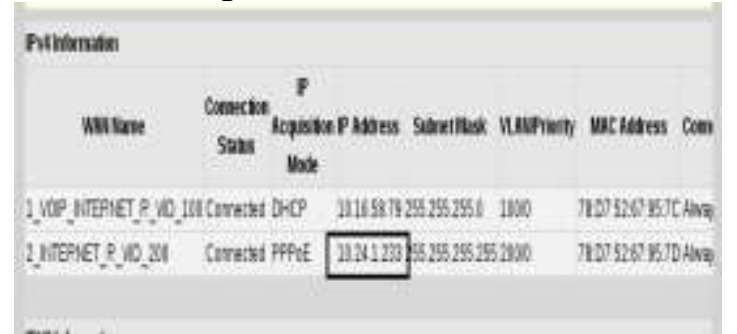

JURSIMA

Jurnal Sistem Informasi dan Manajemen https://ejournal.giciku.ac.id/ STMIK GICI 
Volume 5 No. 2

November 2017

\section{Gambar 4.3 IP yang didapat dari Indihome}

Walaupun setelah dicek di mesin pencari, memang mesin pencari tersebut dapat mendeteksi alamat IP Publik yang kita gunakan, akan tetapi alamat IP Publik ini tidak masuk ke dalam router yang dimiliki oleh CV Pacific Computer.

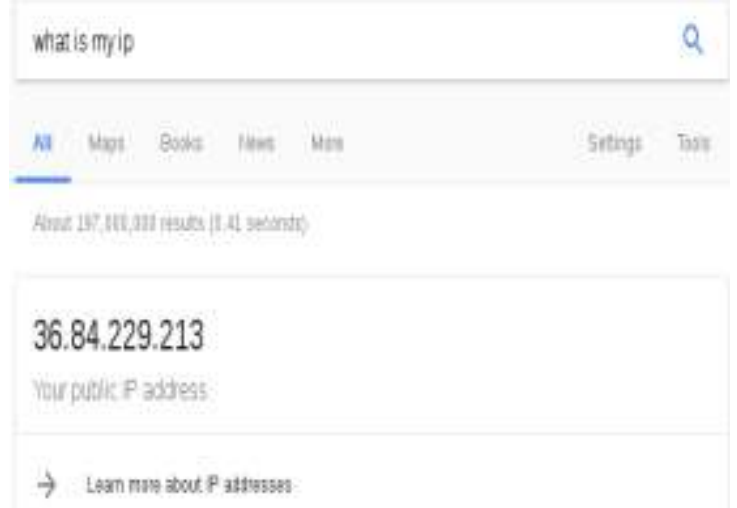

Gambar IP Publik dalam jaringan CV Pacific Computer

Masalah yang terjadi diatas sebenarnya saat ini masih dapat diselesaikan dengan melakukan mulai ulang router yang dimiliki beberapa kali hingga mendapatkan IP Publik Dinamis tersebut. Namun hal ini tidak mungkin selalu dilakukan karena pengguna tidak tahu kapan akan terjadi gangguan seperti ini lagi. Tidak mungkin diadakan monitor selama 24 jam untuk mensiasati kasus ini. Sehingga penulis harus memikirkan jalan keluar atas semua masalah yang timbul atas gangguan ini.

\section{Analisis Sistem yang Diusulkan}

Dengan IP Publik yang tidak disediakan oleh ISP Telkom untuk paket tertentu maka cara mendapatkan IP Publik tanpa perlu berlangganan paket internet yang sangat mahal yaitu dengan mendapatkan IP Publik dari sebuah layanan berbasis awan (cloud) bernama "Biznet GioCloud", beserta bantuan dari Mikrotik RB750R2, dan beberapa command untuk iptables agar bisa menjalankan port forwarding.

Setelah masalah yang terjadi sebelumnya diselesaikan sementara dengan memulai ulang router, penulis memulai penelitian selama beberapa minggu untuk mencari cara mendapatkan IP Publik tanpa perlu berlangganan paket internet yang sangat mahal, hingga muncullah sebuah ide untuk mendapatkan IP Publik dari sebuah layanan berbasis awan (cloud) bernama "Biznet GioCloud", beserta bantuan dari Mikrotik RB750R2, dan beberapa command untuk iptables agar bisa menjalankan port forwarding.

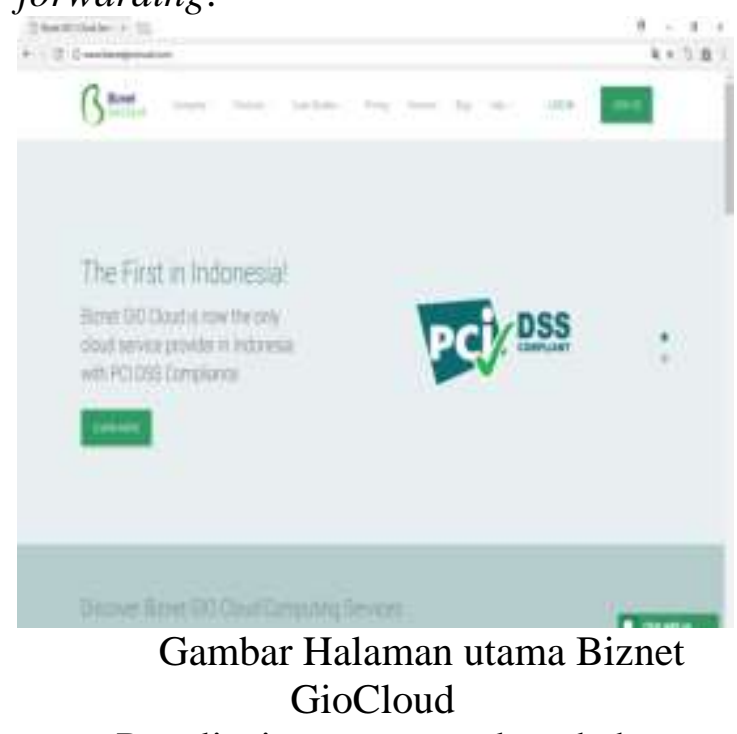

Penulis juga menemukan beberapa penyedia layanan awan lainnya, namun tidak ada yang cocok karena mayoritas layanan tersebut berada diluar negeri, bukan di Indonesia. Ada juga beberapa yang layanannya berada di Indonesia, namun ada keterbatasan seperti membatasi kecepatan internet untuk lalu lintas ke luar negeri yang signifikan
JURSIMA

Jurnal Sistem Informasi dan Manajemen https://ejournal.giciku.ac.id/ STMIK GICI 
ISSN 2338-1523

E-ISSN 2541-576X

Volume 5 No. 2

November 2017

(lambat). Sehingga penulis memilih "Biznet GioCloud" setelah mengujinya dengan layanan pihak ketiga, yaitu speedtest

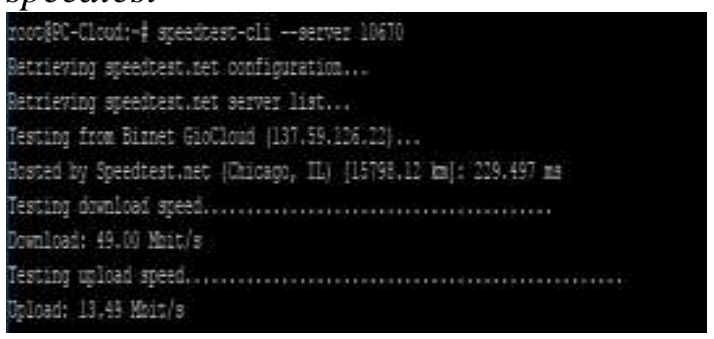

Gambar Hasil speedtest-cli ke Chicago, Amerika serikat

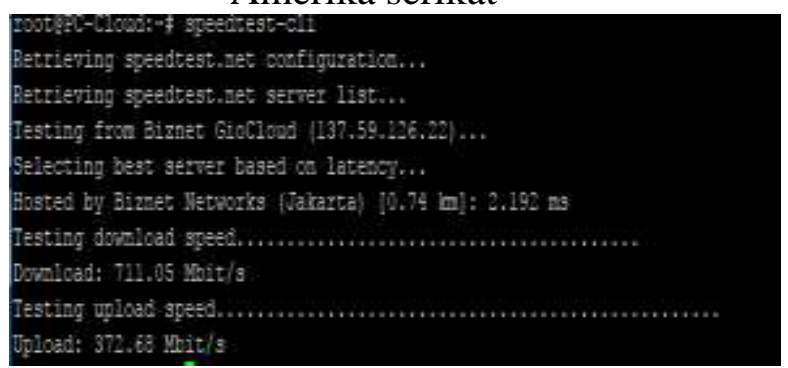

Gambar Hasil speedtest-cli ke Biznet (Jakarta)

Dari hasil speedtest diatas dapat disimpulkan bahwa internet yang dimiliki kantor lebih lambat dari hasil-hasil diatas, sehingga cocok untuk penggunaan dikantor CV Pacific Computer.

\subsection{Implementasi}

Untuk mengatasi permasalahan dalam mendapatkan IP Publik dari layanan peladen berbasis awan (Cloud Server) dengan bantuan VPN, port forwarding. Seperti gambar dibawah ini

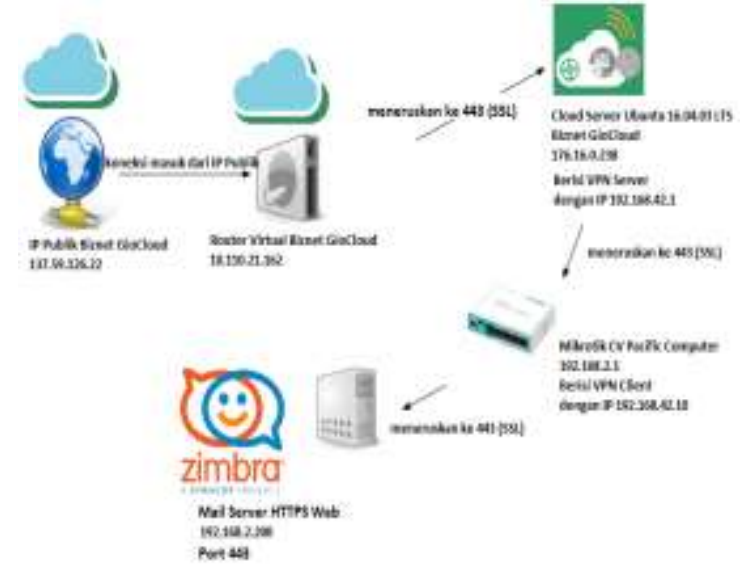

Gambar Skema Koneksi Mail Server CV Pacific Computer saat ini

\section{Merancang Sistem Koneksi IP Publik}

Berikut ini adalah langkahlangkah yang dilakukan agar Mail Server CV Pacific Computer dapat berkomunikasi kembali dengan adanya IP Publik yang baru.

\section{Konfigurasi VPN Server}

Konfigurasi yang dilakukan di Biznet GioCloud adalah sebagai berikut :
1. Lakukan login ke biznetgiocloud.com

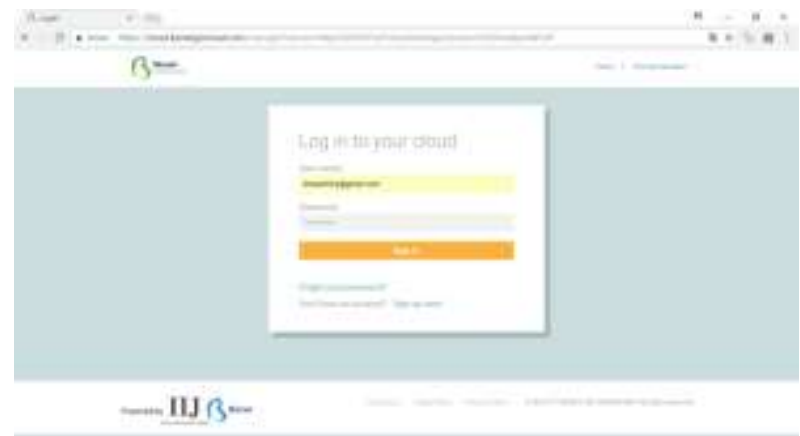

Gambar Tampilan Halaman Login Biznet GioCloud

2. Setelah berhasil masuk, dari menu Dashboard klik ke menu Catalog
JURSIMA

Jurnal Sistem Informasi dan Manajemen https://ejournal.giciku.ac.id/ STMIK GICI 
ISSN 2338-1523

E-ISSN 2541-576X

Volume 5 No. 2

November 2017

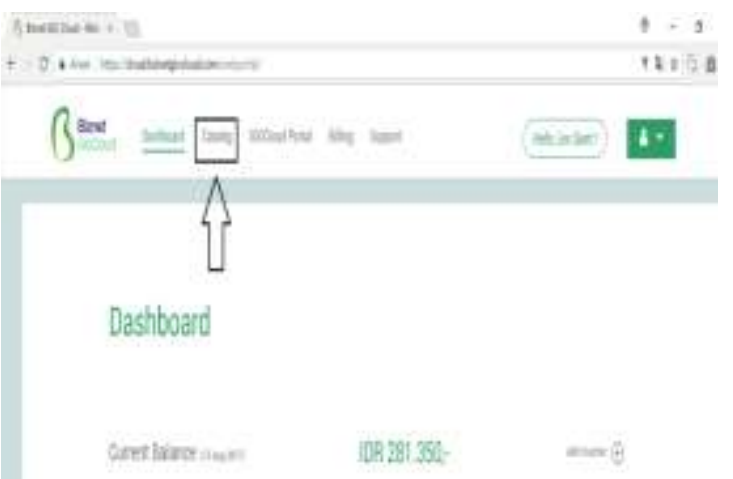

Gambar Tampilan Halaman Dashboard

3. Pilih katalog yang diinginkan, disini penulis memilih sistem operasi Ubuntu

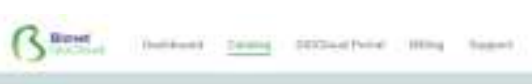

Catalog

bioclaud

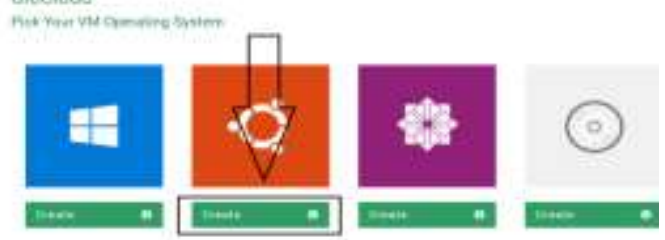

Gambar Pilihan Katalog

4. Isi semua kolom yang diperlukan, pilih spesifikasi virtual server yang diinginkan

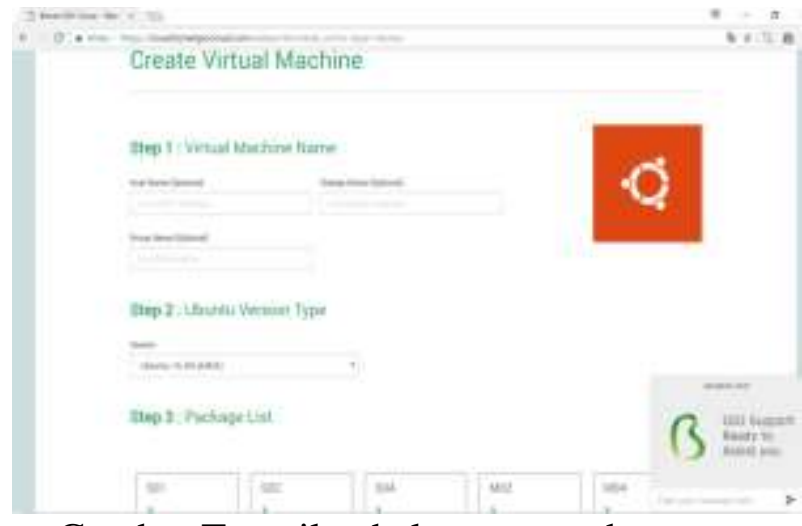

Gambar Tampilan halaman membuat Virtual Machine

5. Setelah data diisi dan spesifikasi virtual machine sudah dipilih, scroll tetikus kebawah, dan akan muncul menu estimasi pembayaran per jam, per per hari, hingga per bulan

\section{Billing Estimation}

Gambar Tampilan Estimasi biaya

6. Setelah virtual machine selesai dibuat, maka kembalilah ke menu dashboard, akan ada tampilan seperti dibawah ini, kemudian pilih logo matikan, setelah virtual machine mati, pilih gembok untuk
JURSIMA

Jurnal Sistem Informasi dan Manajemen https://ejournal.giciku.ac.id/ STMIK GICI 
ISSN 2338-1523

E-ISSN 2541-576X

Volume 5 No. 2

November 2017

menyetel ulang kata sandi peladen virtual agar dapat masuk kedalam peladen. Simpan baik-baik kata sandi tersebut.

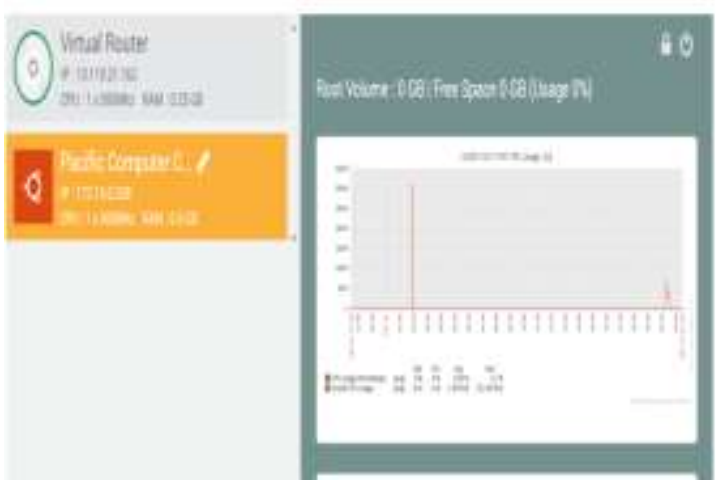

Gambar Tampilan Dashboard Biznet GioCloud

7. Klik my ip address list, kemudian teruskanlah port 22 ke publik, dalam hal ini penulis meneruskannya ke port 888 demi keamanan. Karena di Internet para peretas selalu memindai port 22 .

Gambar port forwarding pada Biznet GioCloud

8. Masuklah ke peladen ubuntu tersebut, melalui IP Publik yang ada di halaman my ip address list

\section{IPAddress List}

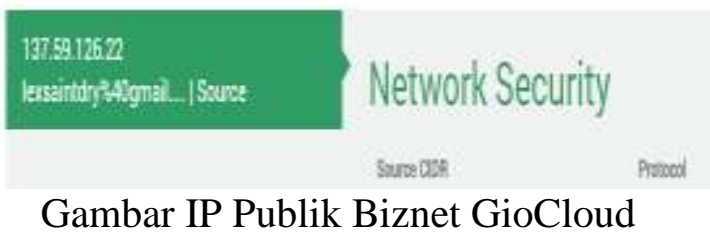

JURSIMA

Jurnal Sistem Informasi dan Manajemen
9. Masukkan alamat 137.59.126.22 kedalam putty dengan port 888 kemdian pilih open. Jika muncul peringatan keamanan, pilih yes
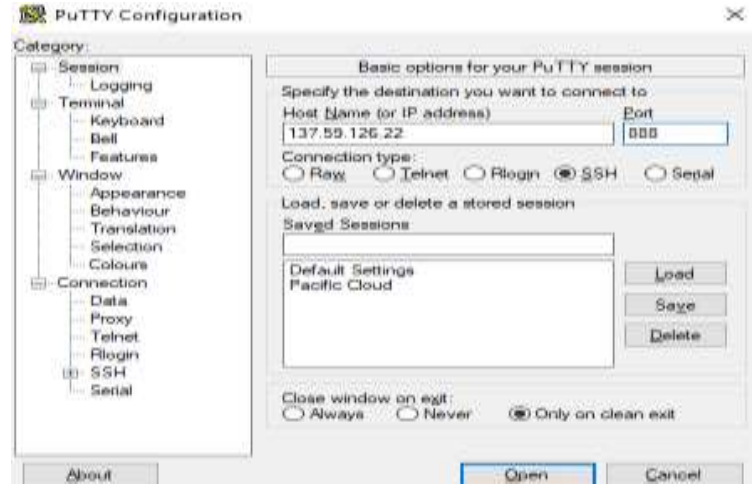

Gambar Tampilan Putty koneksi Biznet

GioCloud

10. Masuklah sebagai root kemudian isikan kata sandi yang telah didapatkan sebelumnya, kemudian masukkan perintah "passwd" untuk merubah kata sandi jika diperlukan

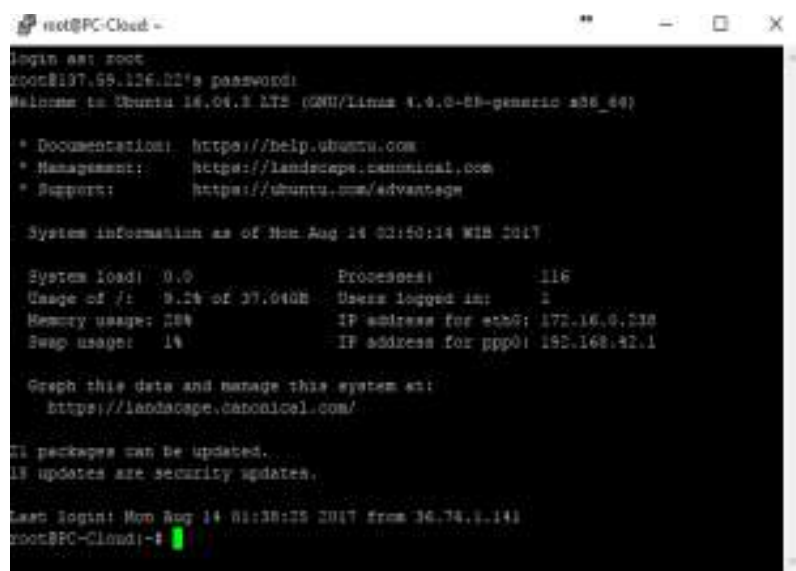

Gambar Tampilan Peladen melalui Putty

11. Masukkan perintah "apt-get update", kemudian masukkan perintah "apt-get dist-upgrade" untuk memperbarui sistem secara menyeluruh. 
Volume 5 No. 2

November 2017

12. Masukkan perintah dibawah ini :

wget https://git.io/vpnsetup -O vpnsetup.sh nano -w vpnsetup.sh

13. Ubah isian dalam vpnsetup.sh seperti dibawah ini :

\# All values MUST be placed inside 'single quotes'

\# DO NOT use these characters within values: \" '

wget https://git.io/vpnsetup -O vpnsetup.sh \&\& sudo 1

VPN_IPSEC_PSK='your_ipsec_p re_shared_key' I

VPN_USER='your_vpn_username '।

VPN_PASSWORD='your_vpn_pa ssword' sh vpnsetup.sh

14. Lakukan port forwarding UDP 500 dan UDP 4500. VPN siap digunakan.

\section{Konfigurasi pada Mikrotik CV Pacific Computer sebagai VPN Klien}

1. Masuklah ke Mikrotik via Winbox, kemudian pilih menu PPP $\rightarrow>$ pilih tambah berwarna biru $\rightarrow$ pilih L2TP Client

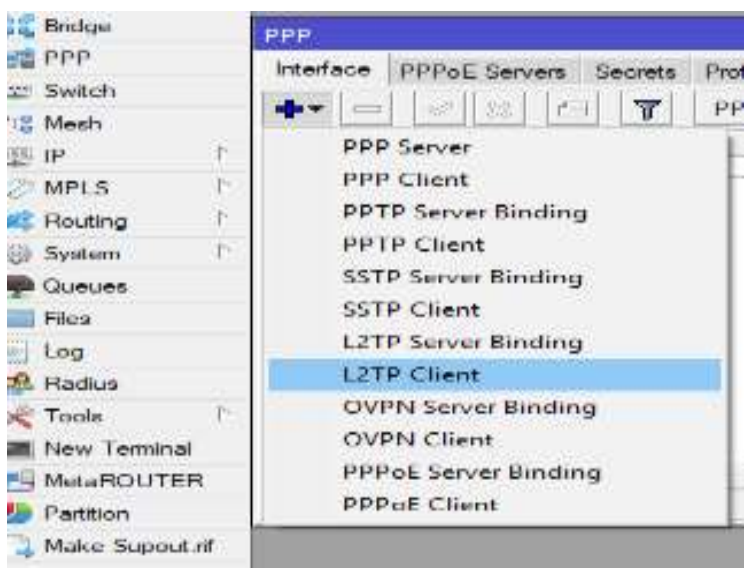

JURSIMA

Jurnal Sistem Informasi dan Manajemen
Gambar Konfigurasi VPN Client

L2TP/IPSec pada Mikrotik-1

2. Pada tab dial out, isilah connect to dengan IP Publik, user, password yang telah dibuat sebelumnya, centang "Use IPSec" kemudian isi IPSec Secret yang telah dibuat sebelumnya, centang allow : mschap2, mschap1, chap, pap, kemudian klik OK
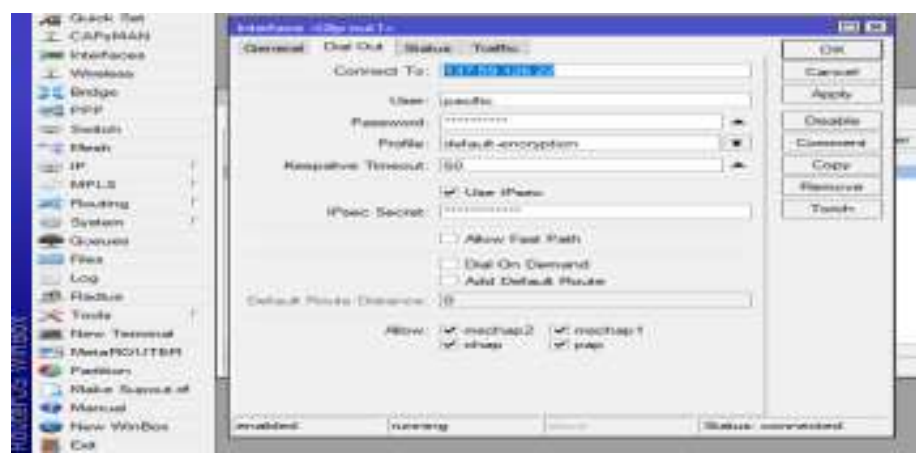

Gambar Konfigurasi VPN Client L2TP/IPSec pada Mikrotik-2

3. VPN Klien telah selesai dikonfigurasi, untuk mengujinya, silahkan ping ke 192.168.42.1 melalui Mikrotik

\section{Konfigurasi pada Peladen Surat Elektronik CV Pacific Computer}

Konfigurasi pada peladen surat elektronik CV Pacific Computer tidak diperlukan, kecuali ada pergantian alamat IP.

Konfigurasi port forwarding

1. Pada Mikrotik, pilih menu IP -> Firewall -> NAT. Tambahkan sebuah NAT Rule seperti dibawah ini :

Tab GENERAL :

Chain : dstnat.

Dst Address : 192.168.42.10 ( IP VPN Klien ). 
ISSN 2338-1523

E-ISSN 2541-576X

Volume 5 No. 2

November 2017

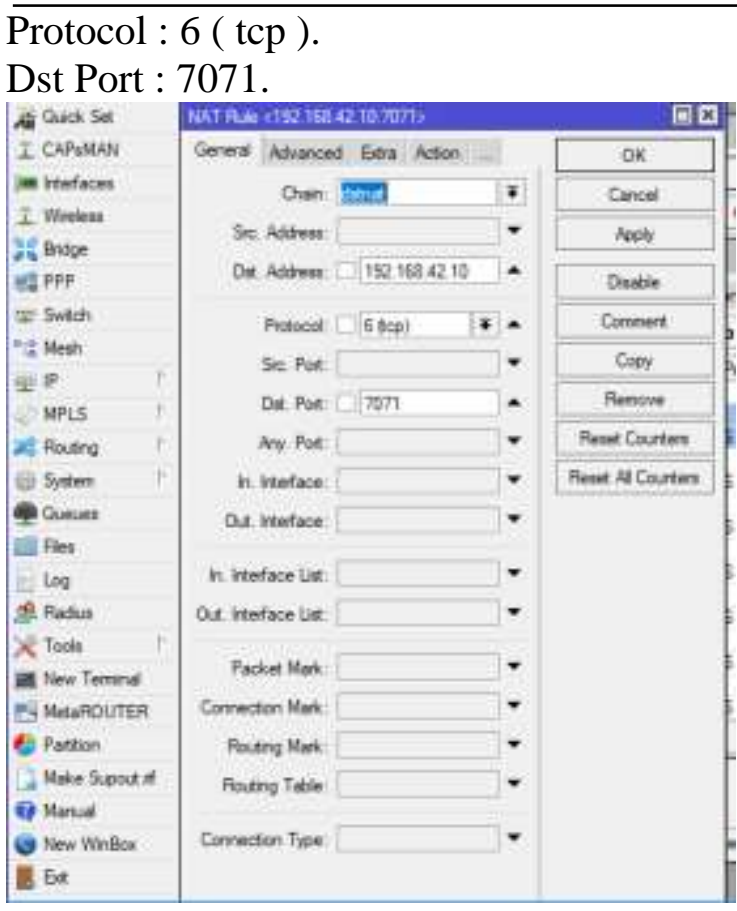

Gambar port forwarding tab General

Tab ACTION :

Action : dst-nat.

To Address : 192.168.2.200 ( IP Peladen

Surat Elektronik).

To Port : 7071.

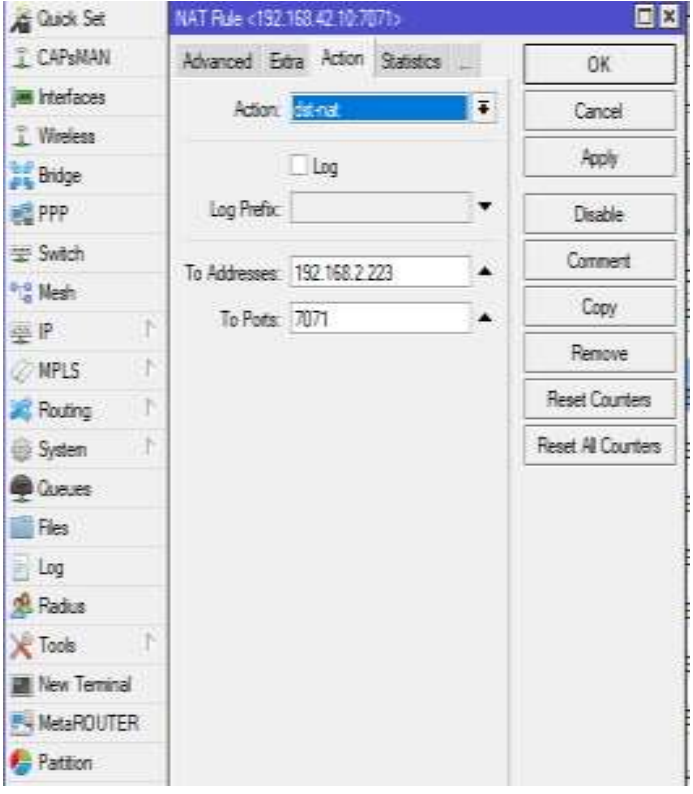

Gambar port forwarding tab action

Contoh diatas merupakan contoh untuk port 7071 sebagai zimbra admin

2. Lakukan hal yang sama untuk port lainnya yang diperlukan pada peladen surat elektronik $(25,995,993,110,143,587,465)$.

3. Lakukan port forwarding disisi peladen Ubuntu di Biznet GioCloud dengan perintah seperti dibawah ini :

iptables -t nat -A PREROUTING -d 172.16.0.238 -p tcp --dport 7071 -j DNAT --to-dest 192.168.42.10:7071 iptables -t nat -A POSTROUTING -d 192.168.42.10 -p tcp --dport 7071 -j SNAT --to-source 192.168.42.1

4. Lakukan perintah yang sama untuk port lainnya yang diperlukan pada peladen surat elektronik $(25,995,993,110,143,587,465)$.
JURSIMA

Jurnal Sistem Informasi dan Manajemen https://ejournal.giciku.ac.id/ STMIK GICI 
ISSN 2338-1523

E-ISSN 2541-576X

Volume 5 No. 2

November 2017

5. Konfigurasi port forwarding pada halaman web Biznet GioCloud di my ip address list seperti gambar dibawah ini :

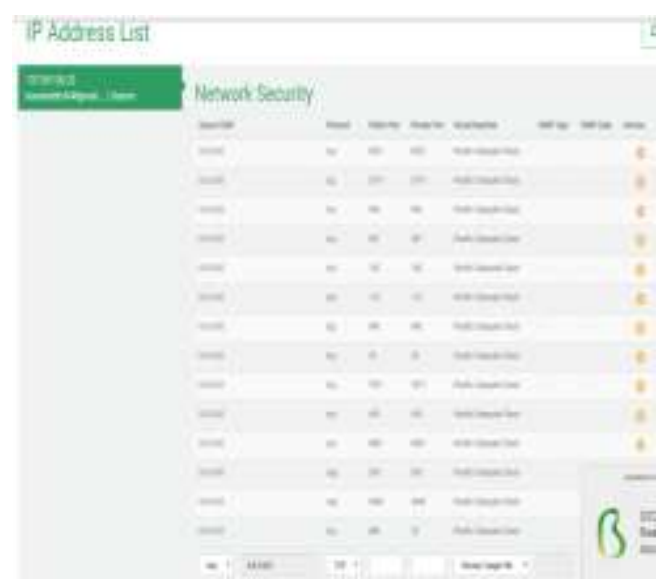

Gambar port forwarding Biznet GioCloud

6. Lakukan perubahan alamat IP pada domain yang dimiliki. Dalam kasus ini penulis mengubah alamat mail.pacific-computer.co.id ke 137.59.126.22 dengan sebelumnya beralamat di flavabatam.dyndns.tv

7. Lakukan ujicoba. Dalam hal ini penulis menguji coba mengunjungi https://mail.pacificcomputer.co.id dan https://137.59.126.22

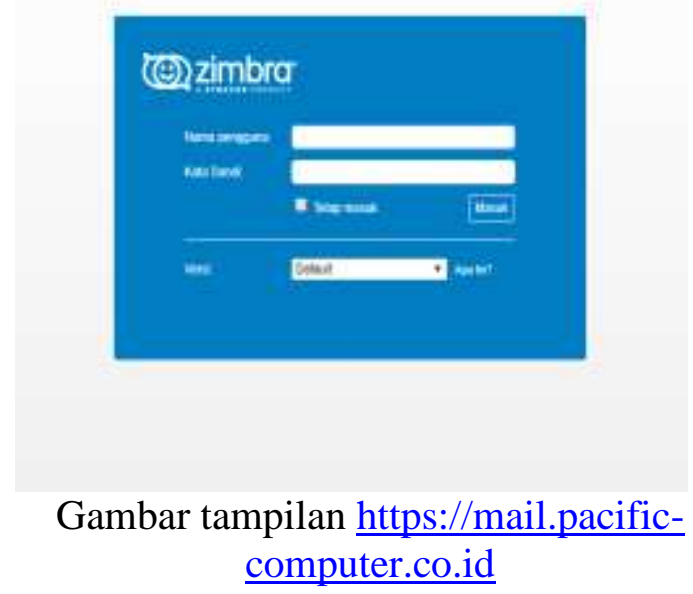

8. Port forwarding dan VPN telah berhasil. Peladen surat elektronik CV Pacific Computer telah berubah menggunakan alamat IP Publik milik peladen awan Biznet GioCloud

\section{HASIL DAN PEMBAHASAN}

Untuk mengatasi permasalahan dalam mendapatkan IP Publik dari layanan peladen berbasis awan (Cloud Server) dengan bantuan VPN, port forwarding. Seperti gambar dibawah ini

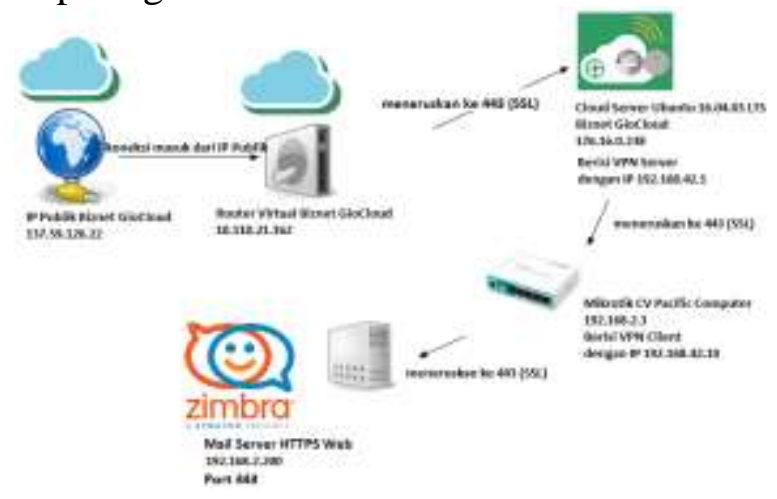

JURSIMA

Jurnal Sistem Informasi dan Manajemen https://ejournal.giciku.ac.id/ STMIK GICI 
Volume 5 No. 2

November 2017

Gambar Skema Koneksi Mail Server CV Pacific Computer saat ini.

\section{Merancang Sistem Koneksi IP Publik}

Berikut ini adalah langkah-langkah yang dilakukan agar Mail Server CV Pacific Computer dapat berkomunikasi kembali dengan adanya IP Publik yang baru.

Konfigurasi VPN Server, Pada permasalahan yang ada peneliti memakai layanan berbasis awan (cloud) bernama "Biznet GioCloud", Lakukan login ke situs biznetgiocloud.com. Konfigurasi pada Mikrotik CV Pacific Computer sebagai VPN Klien. Pada sistem Mikrotik via Winbox, kemudian pilih menu PPP -> pilih tambah berwarna biru -> pilih L2TP Client. Pada tab dial out, isilah connect to dengan IP Publik, user, password yang telah dibuat sebelumnya, centang "Use IPSec" kemudian isi IPSec Secret yang telah dibuat sebelumnya, centang allow : mschap2, mschap1, chap, pap, kemudian klik OK. Maka VPN Klien telah selesai dikonfigurasi, untuk mengujinya, silahkan ping ke 192.168.42.1 melalui Mikrotik.

\section{Konfigurasi pada Peladen Surat Elektronik CV Pacific Computer}

Konfigurasi pada peladen surat elektronik CV Pacific Computer tidak diperlukan, kecuali ada pergantian alamat IP. Tambahkan sebuah NAT Rule seperti dibawah ini :

\section{Tab GENERAL :}

Chain : dstnat.

Dst Address : 192.168.42.10 ( IP VPN

Klien ).

Protocol : 6 ( tcp ).

Dst Port : 7071.
Contoh diatas merupakan contoh untuk port 7071 sebagai zimbra admin

1.Lakukan hal yang sama untuk port lainnya yang diperlukan pada peladen surat elektronik $(25,995,993,110,143,587,465)$.

2.Lakukan port forwarding disisi peladen Ubuntu di Biznet GioCloud dengan perintah seperti dibawah ini :

iptables -t nat -A PREROUTING -d 172.16.0.238 - p tcp --dport 7071 -j DNAT --to-dest 192.168.42.10:7071

iptables -t nat -A POSTROUTING -d 192.168.42.10 -p tcp --dport 7071 -j SNAT --to-source 192.168.42.1

3. Lakukan perintah yang sama untuk port lainnya yang diperlukan pada peladen surat elektronik $(25,995,993,110,143,587,465)$.

4. Konfigurasi port forwarding pada halaman web Biznet GioCloud di my ip address list seperti gambar dibawah ini :
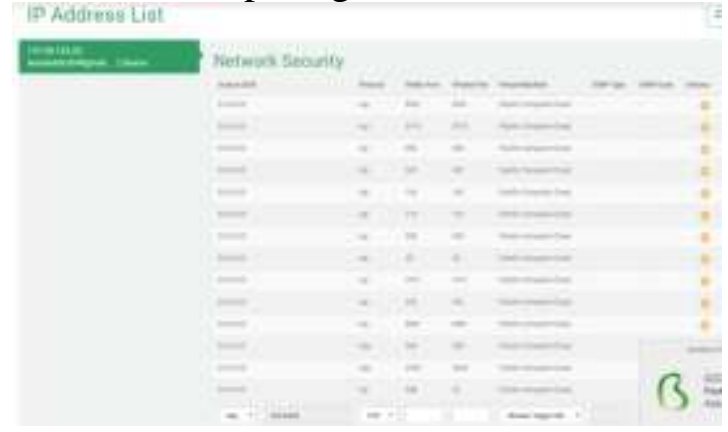

Gambar Port forwarding di web biznet

5.Lakukan perubahan alamat IP pada domain yang dimiliki. Dalam kasus ini penulis mengubah alamat mail.pacificcomputer.co.id ke 137.59.126.22 dengan sebelumnya beralamat di flavabatam.dyndns.tv

6.Lakukan ujicoba. Dalam hal ini penulis menguji coba mengunjungi
JURSIMA

Jurnal Sistem Informasi dan Manajemen https://ejournal.giciku.ac.id/ STMIK GICI 
Volume 5 No. 2

November 2017

https://mail.pacific-computer.co.id dan https://137.59.126.22

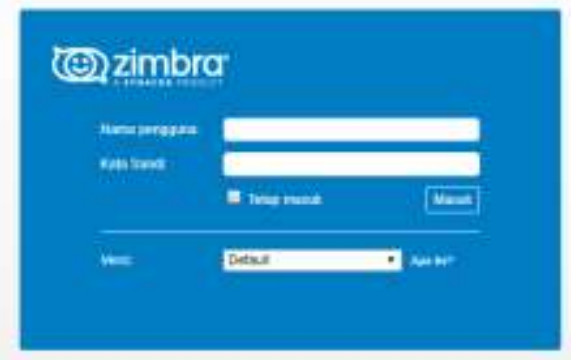

Gambar tampilan https://mail.pacificcomputer.co.id

Port forwarding dan VPN telah berhasil. Peladen surat elektronik CV Pacific Computer telah berubah menggunakan alamat IP Publik milik peladen awan Biznet GioCloud

\section{SIMPULAN}

Berdasarkan pembahasan dan evaluasi dari bab-bab sebelumnya, maka dapat diambil kesimpulan sebagai berikut :

1. Cara memanfaatkan alamat protokol internet publik statis yang tersedia di Peladen berbasis Awan (Cloud Server) supaya dapat dimanfaatkan di Peladen milik CV Pacific Computer adalah dengan mengkonfigurasi Peladen di Biznet GioCloud dan di Mikrotik milik CV Pacific Computer supaya saling terhubung sehingga membentuk sebuah sistem jaringan.

2. Cara menghubungkan Peladen berbasis awan (Cloud Server) dengan Peladen milik CV Pacific Computer adalah dengan menggunakan VPN ditambah metode Port forwarding ke Peladen awan (Cloud Server) milik Biznet GioCloud, maka IP Publik Biznet GioCloud dapat digunakan pada peladen surat elektronik milik CV Pacific Computer

\section{UCAPAN TERIMA KASIH}

Peneliti mengucapkan terima kasih kepada berbagai pihak yang telah membantu penulis menyelesaikan penulisan ini. Terima kasih kepada Pimpinan CV Pacific Computer yang telah meluangkan waktunya untuk peneliti melakukan penelitian ini dan kepada rekan dan karyawan yang telah bersedia untuk penulis wawancarai dan terakhir terima kasih kepada TIM LPPM STMIK GICI.

\section{DAFTAR PUSTAKA}

Burgess, Dennis. 2009. Learn RouterOS. Missouri : Link Technologies, Inc.

Gupta, Pankaj. et al. 2014. Operating System. Haryana : Dronacharya College of Engineering India.

MADCOMS. 2016. Manajemen Sistem Jaringan Komputer dengan Mikrotik RouterOS. Yogyakarta : ANDI OFFSET.

Nugroho, Kukuh. 2016. Jaringan Komputer menggunakan Pendekatan Praktis. Kebumen : MEDIATERA

Singh, Dr. Anil Kumar. Internet Protocol (IP) Address - Subnetting and Supernetting. Uttar Pradesh : Jagran Institute of Management India

Sridevi. et al. 2013. Security in Virtual Private Networks. Karnatak : Department of Computer Science Karnatak University India.
JURSIMA

Jurnal Sistem Informasi dan Manajemen https://ejournal.giciku.ac.id/ STMIK GICI 